\title{
Behold the best and worst of me: the impostor phenomenon and academic behavior in the business area ${ }^{\star, * *}$
}

\author{
Alison Martins Meurer ${ }^{1,2}$ \\ (D) https://orcid.org/0000-0002-3704-933X \\ E-mail: alisonmmeurer@gmail.com \\ Flaviano Costa $^{3}$ \\ (D) https://orcid.org/0000-0002-4694-618X \\ E-mail: flaviano@ufpr.br
}

\begin{abstract}
1 Universidade Federal do Paraná, Programa de Pós-Graduação em Contabilidade, Curitiba, PR, Brazil
2 Universidade Estadual de Ponta Grossa, Departamento de Contabilidade, Ponta Grossa, PR, Brazil

3 Universidade Federal do Paraná, Departamento de Ciências Contábeis, Curitiba, PR, Brazil
\end{abstract}

Received on 08.08.2019 - Desk acceptance on 08.16.2019 - $2^{\text {nd }}$ version approved on 10.28.2019 - Ahead of print on 03.02.2020

Associate Editor: Jacqueline Veneroso Alves da Cunha

\begin{abstract}
The aim of this study was to analyze the relationship between the impostor phenomenon (IP) and the academic behavior of stricto sensu postgraduate students in business area courses. Discussing the relationship between psychological variables and student academic behavior is a topic of interest as empirical evidence indicates that these variables affect the environment in which scientific research is developed. It is important to look for elements that help in understanding the IP in order to reduce its impacts on the performance, behavior, and feelings of students. Postgraduate students enrolled in stricto sensu courses may be refusing opportunities to advance in their professional careers and adopting behaviors that are discordant with those desired by universities because they feel like impostors in terms of their abilities. Besides the relevance of the relationships analyzed, this research also uses the Meurer and Costa Scale of Academic Behaviors - Stricto Sensu (MCSABSS), which can measure academic behaviors displayed in Brazilian postgraduate courses, enabling the development of new investigations into the topic. The population includes postgraduates enrolled in 2018 in academic master's, professional master's, and academic doctorate courses in administration, accounting, and economics, known as the business area. The data collection was operationalized via a survey carried out online, which obtained 1,816 valid participations. The data were analyzed using descriptive statistics, exploratory factor analysis, and the Spearman's correlation. Higher levels of impostor feelings are positively associated with displays of counterproductive academic behaviors and are mostly negatively associated with academic citizenship behaviors. After identifying the IP in students, actions to minimize these feelings can be implemented, given that postgraduate students with the IP may not be engaging in the activities that permeate stricto sensu, thus damaging the climate and culture of cooperation needed in academia.
\end{abstract}

Keyword: impostor phenomenon, academic behavior, business area.

Correspondence address

Alison Martins Meurer

Universidade Federal do Paraná, Programa de Pós-Graduação em Contabilidade

Avenida Prefeito Lothário Meissner, 632 - CEP 80210-170

Jardim Botânico - Curitiba - PR - Brazil

\footnotetext{
* Paper presented at the XIX USP International Conference in Accounting, São Paulo, SP, Brazil, July of 2019.

** This study was carried out with support from the Coordination for the Improvement of Higher Education Personnel - Brazil (Capes) - Funding Code 001
} 


\section{INTRODUCTION}

Although the formal and informal structures of higher education organizations and the profile of students and teachers have changed since the 2000s, the ways of observing and evaluating student performance and behavior have remained practically unaltered, neglecting relevant elements that interfere in the running of a more effective teaching environment (Islam, Permzadian, Choudhury, Johnston, \& Anderson, 2018; Meriac, 2012). Meriac (2012) recognizes the importance of transcending quantitative aspects, such as grades in the disciplines, and also observing aspects relating to the discretionary behaviors displayed by students in the academic environment, which even though they include non-obligatory attitudes are important for teaching institutions and for students, since they relate to shaping the environment in which the teaching-learning process occurs.

Discussions about discretionary behaviors practiced through the individual's power of choice received more attention at the end of the 1980s and during the 1990s, as the investigations expanded into the consequences of interpersonal relationships in terms of task results and organizational performance. The pioneering study by Organ (1988) addressed the organizational citizenship behavior that is characterized by actions that are not formally required, but which contribute to an organization's effective functioning and long-term results. Other studies went on to also address counterproductive work behaviors, which refer to attitudes that are potentially prejudicial to colleagues or to organizations (Spector \& Fox, 2002) and that may contribute to organizational disengagement (Meriac, 2012).

Researchers (e.g., Allison, Voss, \& Dryer, 2001; Meriac, 2012) have transposed these constructs to the educational context, using different nomenclatures to discuss citizenship and counterproductive behaviors in the university environment. In this investigation, the descriptions "academic citizenship behavior" (ACB) and "counterproductive academic behavior" (CAB) are adopted, which form a general construct known here as "academic behavior."

Examples of ACB include involvement in civic activities, carrying out actions with the external community, and helping fellow students with difficulties in learning some content. In contrast, $\mathrm{CAB}$ is characterized by attitudes of academic cheating, such as arriving late, providing answers to fellow students, and practicing plagiary, among other actions that promote academic disengagement (Allison et al., 2001; Meriac, 2012).
Within the university context, it has been discovered that the citizenship behavior of students (Meriac, 2012) and teachers (Khalid, Jusoff, Othman, Ismail, \& Rahman, 2010) is related to students' academic performance, and that life satisfaction predicts their citizenship behavior (Gore et al., 2014). With relation to the antecedents of CABs, evidence has shown that characteristics of the student's personality (Credé \& Niehorster, 2009; Islam et al., 2018), a sense of impunity in cases of academic cheating, and the area of knowledge of the higher education course (Freire, 2014) may be related to counterproductive attitudes. Under the same focus, Organ and Ryan (1995) recognize that personality traits strongly predict discretionary behaviors.

Thus, among the various personality traits studied in the literature, the impostor phenomenon (IP) emerges as a subject of interest in the studies on the attribution process that addresses perceptions of obtained successes or failures and has received attention in recent decades in higher education, especially since the 2000 s, due to the growing debates regarding personality traits related to perceptions of academic success (Sonnak \& Towell, 2001).

Conceptually, the IP is used to define people who are insecure in relation to their competence, given that they tend to attribute their success to luck or other variables that go beyond their abilities. People with impostor feelings overcome their perceptions of a lack of competence by means of workaholic or procrastination behaviors, high standards of success, and not delegating tasks (Clance \& Imes, 1978). Just like the discretionary behaviors that shape the person-environment relationship, it is believed that the range of effects of the IP can interfere in the way the individual deals with the challenges and situations experienced in the higher education environment (Chassangre \& Callahan, 2017; Dudău, 2014).

Thus, higher education is characterized by more academic demands and less external control (Islam et al., 2018), requiring autonomy on the part of the student. Regarding stricto sensu postgraduation, this educational level has been characterized by its complexity, multiple objectives, and social relations, which exert pressures on and create expectations from students (Levecque, Anseel, De Beuckelaer, Van der Heyden, \& Gisle, 2017), and this can foster impostor feelings and interfere in the quality of life and performance of students/researchers. According to the Center for Teaching Excellence of the University of Waterloo (2016), postgraduates with impostor feelings tend to be less accessible to students, present a low capacity to motivate and carry out the role of student mentor, 
conduct less scientific research, and avoid departmental roles. These behaviors among professionals whose abilities are hampered by the IP lead to an environment that is less conducive to knowledge development.

Due to the particular characteristics and fears derived from the IP, it is believed that students with higher levels of these feelings may shape their academic behavior to achieve their objectives, such as avoiding judgements and carrying out self-sabotage, described by the term "self-handicapping," to justify their faults (Cowman \& Ferrari, 2002). The problem emerges from the possibility of these feelings undesirably affecting the way academic behaviors are externalized or inhibited. Specifically in relation to administration, accounting, and economics courses, known in this study as the business area, attention has been paid to students, since the empirical evidence indicates a greater propensity of academics in the business area to engage in counterproductive attitudes that are misaligned with the aims of their teaching institutions (McCabe, Butterfield, \& Treviño, 2006).

Thus, discussions regarding specifications of the stricto sensu postgraduation environment, the IP, and academic behavior are appropriate in order to intensify the debates and enable an understanding of the possible relationships between these elements. Within that context, this study emerges and sheds light on the following research question: What is the relationship between the impostor phenomenon and the academic behavior of stricto sensu postgraduate students in business area courses? The aim of the research consists of analyzing the relationship between the IP and the academic behavior of stricto sensu postgraduate students in business area courses.

The research is warranted as the labor market values and desires different characteristics that can promote organizational performance. These include positive voluntary attitudes that characterize citizenship behaviors. Preparing professionals in the business area and incentivizing their engagement in positive attitudes can help in present academic performance and collaborate in these students' professional success, as well as aligning the competences developed at university with those desired by the professional market (Allison et al., 2001). In addition, teaching institutions that seek to foster appropriate academic behaviors prepare students for the labor market more effectively, they improve their internal evaluations, and they maintain teaching quality (Elsharnouby, 2015). It is also noted that calls for ethical attitudes have intensified with relation to business area courses, especially after the scandals that have occurred since the 2000s (e.g., Enron and WorldCom), which exposed society to the risks of deviant manager behaviors (Freire, 2014). In stricto $s e n s u$, the aspiration for ethical conduct from students is even more stimulated, as it concerns training future teachers and researchers who can dictate the direction of educational training and the development of scientific knowledge in the country.

\section{THEORETICAL FRAMEWORK}

\subsection{Impostor Phenomenon}

The IP derives from the studies that were begun in the 1970s by Drs. Pauline Rose Clance and Suzanne Imes, researchers at the Georgia State University in the city of Atlanta (Georgia, United States of America) at the time. The initial observations indicated that female employees and students who showed satisfactory performance when executing their tasks presented insecurities and doubts in relation to their competences and successes, they felt like "impostors," and they feared that others would discover their intellectual limitations and inabilities (Clance \& Imes, 1978; Taylor, 2009). Positive experiences were not internalized as being the result of genuine abilities, but of random factors or manipulative attitudes (Langford \& Clance, 1993). These behaviors and feelings were called the IP.

The study by Clance and Imes (1978) began discussions inherent to the IP and exposed the need to extend the studies on this personality trait given its ability to limit the individual's development. The construction of subclinical scales (Clance, 1985; Harvey, 1982; Imes, 1980), including the Clance Impostor Phenomenon Score (CIPS), promoted the development of research in different samples and environments, widening the discoveries and conceptions relating to the topic. The cumulative findings indicated behavioral traits that relate with the IP, elements that contribute to an accentuation of feelings of impostorism, and the existence of behavioral characteristics shared by those burdened with impostor fears.

Impostors tend to share behavioral attitudes involving feelings of inauthenticity and a search for social approval (Cokley et al., 2015; Kets de Vries, 1989; Li, Hughes, \& Thu, 2014; Parkman, 2016), which cause this internal experience to be maintained. In this sense, the IP has multiple etiological factors and specific characteristics that affect the individual's well-being and mental health (Chassangre, 2014), such as introversion, 
generalized anxiety, difficulties accepting complements, underestimation of their abilities, overestimation of the abilities of others, guilt from success, and fear of evaluation and of failure (Chassangre \& Callahan, 2017).

With relation to its scope and the multiple associations between the IP and other emotions and personality traits, studies such as those of Thompson, Foreman, and Martin (2000) and Dudău (2014) reveal the connection between the IP and perfectionism. Thompson et al. (2000) verified in undergraduate students that high impostor feelings are linked to increased worries, with the possibility of making mistakes, and with higher levels of anxiety. Dudău (2014) discovered that impostors present sensitivity to criticism and pay more attention to mistakes made and not to successes achieved. Thus, perfectionism is presented in the literature as one of the most marked personality traits linked to impostors.

Self-handicapping behaviors have also been analyzed together with the IP. Cowman and Ferrari (2002) indicated that self-handicapping can be adopted by those who feel impostor fears to avoid situations of failure or judgement; while Matos (2014) found a negative association between self-effectiveness beliefs and the IP, indicating a lower selfeffectiveness belief in those who have higher impostor feelings. These interconnections can generate mistaken conclusions in the recognition of individuals who suffer from the IP. In this sense, the behavioral characteristics that distinguish the IP from the other components of human personality can collaborate in an inability to assimilate success, overestimation of the abilities of others, and underestimation of their skills and fear of being "unmasked" and having their faults exposed (Clance \& Imes, 1978; Clance \& O’Toole, 1987).

After understanding the origin of the IP and going into depth regarding the general behaviors and profile of impostors, it is possible to analyze their attitude in specific contexts, such as in the university environment. Thus, the next section aims to discuss the academic behavior of postgraduate students using the concepts of $\mathrm{ACB}$ and $\mathrm{CAB}$.

\subsection{Academic Behavior}

Inspired by the concepts of "willingness to cooperate" (Barnard, 1938) and "spontaneous behaviors" (Katz, 1964; Katz \& Kahn, 1966), the researcher Dennis Organ coined the term "organizational citizenship behavior" to define "individual behavior that is discretionary, not directly or explicitly recognized by the formal reward system, and that in aggregate promotes the effective functioning of the organization" (Organ, 1988, p. 4). When extending the perspective to specific organizational contexts and environments, such as educational organizations, it is perceived that there are still few studies that address these behaviors, with an even smaller number of investigations restricted to higher education, even though there are important indications of their importance in this area.

Most of the research that addresses citizenship behavior in higher education tends to analyze employees' and teachers' perceptions by means of a concentrated focus on the organization, instead of examining the individual's perception and without including students (e.g., Rose, 2012), thus rejecting important research fields that could be explored. Authors such as Schmitt, Oswald, Friede, Imus, and Merritt (2008) emphasize that work and educational environments differ in various aspects, but that variables derived from the psychological and behavioral perspectives are analogous and translatable to the academic environment, including organizational citizenship behavior, called ACB in this study.

From the student perspective, the study by Allison et al. (2001) can be mentioned, which presents examples of citizenship behavior in the university environment, such as helping fellow students, being proactive during classes, volunteering to organize university activities, and encouraging the formation of research groups, among other actions that collaborate in harmonizing the university environment.

Thus, citizenship behaviors can promote more harmony in the academic environment. Williams and Anderson (1991) recognize that ACBs are important for fostering the student's development in the formal or informal university environment and, ultimately, maximizing organizational effectiveness (Gore et al., 2014). Citizenship behavior shapes the context in which students' performance and attitudes are consolidated (Khaola, 2014) and is influenced by psychological elements, such as life satisfaction and well-being (Gore et al., 2014), which can be affected by the IP. When they are satisfied and involved in pleasant university experiences, students are more likely to engage in citizenship behaviors within society and in the organizational environment (Elsharnouby, 2015).

In turn, counterproductive behaviors are characterized by attitudes of disengagement that damage the organization or the organization's members, and can be used as a way to obtain advantages or carry out retaliations (Islam et al., 2018; Spector \& Fox, 2002). Empirical studies (Cummings, Poropat, Loxton, \& Sheeran, 2017; Sackett, Berry, Wiemann, \& Laczo, 2006) and meta-analyses (Dalal, 2005) reveal the independence of counterproductive behavior in relation to citizenship behavior, treating it as a characteristic of the individual that also has the ability to modify the university environment and negatively influence the organizational results and context. 
Disrespecting formal and moral rules and norms determined by the university and teachers, sleeping during class, cheating in evaluations, slandering the teaching institution they study at (Cummings et al., 2017), as well as procrastinating, sabotaging, and insulting (Spector \& Fox, 2002), feature among the characteristics that shape this behavior. These attitudes can be revealed in isolation or presented in day-to-day habits and negligence (Cummings et al., 2017).

Conceptually, terms such as organizational delinquency, aggression, retaliation, and revenge (Spector \& Fox, 2002) are used to characterize attitudes that converge toward counterproductive actions. The scope of such actions and the different theoretical origins contribute to this plurality of terms and conceptual misalignment. As a result, there are discussions in the literature that indicate disparate findings regarding the number and possible dimensions of CAB.

Cummings et al. (2017) verified the existence of a negative relationship between counterproductive behaviors and conscientiousness, pleasantness, and receptiveness and a positive relationship with neuroticism. Thus, organized, persistent, and friendly people who are receptive to new experiences tend to present fewer counterproductive behaviors; this is the opposite of what occurs with those who have low emotional stability and high levels of anxiety, which are characteristics of neuroticism. Citizenship behavior presented a positive relationship with extroversion, indicating that more sociable individuals present, with more intensity, attitudes that transcend the formal role of students and promote well-being in the university environment. The findings also indicate that contextual factors are more related to citizenship behavior than to counterproductive behavior, enabling it to be inferred that the latter is more complex and difficult to modify via external actions originating from peers or teaching institutions than the former.

Thus, citizenship behavior and counterproductive behavior have been presented as variables of interest and effectiveness in the university context (Meriac, 2012). In fact, social gains are noted with the formation of students who are able to promote social well-being through ethical and citizenship actions instead of counterproductive attitudes. The promotion of such behaviors may be related to feelings and psychological characteristics, such as the IP. Thus, the theoretical hypotheses that address this relationship are listed below.

\subsection{Establishment of the Research Hypotheses}

The discussions presented in the literature show that the IP extrapolates feelings experienced internally and influences behaviors exteriorized in social coexistence (Chassangre \& Callahan, 2017; Grubb Iii \& McDowell, 2012; Parkman, 2016). In this sense, impostor fears can limit the propensity of students to run risks and accept more complex tasks, contribute to self-handicapping attitudes, and foster fictitious social behaviors (Clance \& O’Toole, 1987; Kets de Vries, 1989) that perpetuate the student's social image in the eyes of the community with which they coexist. The extent of such behaviors within the academic environment is a concern, given that they may foster citizenship and/or counterproductive attitudes that can influence the performance of the teaching institution, of fellow students, and of the individual who is experiencing impostor feelings.

The literature indicates two theoretical lines that analyze the direction of the relationship between the IP and citizenship behavior. The first is observed in studies such as that of Grubb Iii and McDowell (2012), which hypothesize that individuals who have aspects of the IP may direct efforts toward getting involved in citizenship behaviors so that they appear more engaged and committed to the success and well-being of the organization and those around them, given that they have a high desire for social acceptance. Such behaviors would be adopted as a way of minimizing their inability beliefs and to consolidate their friendliness and involvement in the eyes of others.

However, the empirical results found by Grubb Iii and McDowell (2012) corroborate the second aspect adopted in this study, in which, by presenting fear of failure, people with higher levels of the IP tend to focus intensively on carrying out formal tasks and allocate less time to activities that do not form part of the scope that composes the formal role of the academic, such as citizenship behaviors (Vergauwe, Wille, Feys, De Fruyt, \& Anseel, 2015).

Within this context, by analyzing the relationship between the IP and citizenship behavior among U.S. university employees, Grubb Iii and McDowell (2012) identified that the IP is negatively correlated with citizenship behaviors. Similarly, Vergauwe et al. (2015) identified a negative association between the IP and citizenship behaviors in Belgian business area professionals. Arkan (2016) and Neureiter and TrautMattausch (2016) collaborate the findings by verifying a negative relationship between the levels of impostor feelings and citizenship behaviors of employees in various sectors in Turkey and Austria.

In addition, Zettler (2011) notes that people with higher levels of self-control tend to more frequently present citizenship behaviors, as they foresee the consequences of 
such attitudes in the long run. Within this context, the IP inhibits self-control and the assimilation of success and carrying out of tasks (Chassangre \& Callahan, 2017), indicating the existence of a negative relationship between the IP and ACB. Thus, theoretical hypothesis $1\left(\mathrm{TH}_{1}\right)$ states that:

$\mathrm{TH}_{1}$ : the IP is negatively related with the ACB of stricto sensu students in the business area.

Counterproductive behavior is analogous to attitudes of academic dishonesty. Ferrari (2005) argues that, despite impostors engaging in self-handicapping attitudes, their behaviors do not align with the objectives of academic dishonesty, which seeks success, high rewards, and competition for good grades. However, conceptual elements enable it to be affirmed that selfhandicapping attitudes can be categorized as self-focused counterproductive behaviors (Credé \& Niehorster, 2009), given that they hinder the individual.

In addition, Spector and Fox (2002) and Whelpley and McDaniel (2016) indicate that negative feelings can promote counterproductive behaviors. Thus, as it is related to the internal attitudes of the individual and their sense of social acceptance, the IP can cause dysfunctional behaviors derived from negative emotions, and CABs feature among these attitudes.

In empirical terms, this relationship was observed by Arkan (2016), who identified a positive relationship between higher levels of the IP and counterproductive behaviors. These results are worrying as those behaviors can damage the organization and its members. It warrants mentioning that the investigations that analyze the relationship between the IP and counterproductive behaviors are recent (Arkan, 2016), and it is the interest of this study to contribute to that field of study, especially stricto sensu in the business area. In light of the above, theoretical hypothesis $2\left(\mathrm{TH}_{2}\right)$ states that:

$\mathrm{TH}_{2}$ : the IP is positively related with the CAB of stricto sensu students in the business area.

Thus, it is recognized that the IP may relate with the constructs that form the individual's academic behavior.

\section{METHODOLOGY}

The descriptive research with a quantitative approach was operationalized based on a survey carried out online using the SurveyMonkey ${ }^{\circledR}$ platform. The population consists of students enrolled in stricto sensu academic master's, professional master's, and academic doctorate courses in administration, accounting, and economics in 2018. The data were collected in the period from October to December of 2018.

The data collection instrument was composed of three blocks. Block I measured the IP using the Clance Impostor Phenomenon Scale (CIPS), from Clance (1985). The original version of the CIPS has 20 items with five scores, these being: 1 - not true; 2 - rarely; 3 - sometimes; 4 often; and 5 - very true. Block II focused on measuring academic behavior and for that it was necessary to build a behavioral scale applied to Brazilian stricto sensu courses. The Meurer and Costa Scale of Academic Behaviors Stricto Sensu (MCSAB-SS) was elaborated based on reports and pre-tests carried out with 773 postgraduate students from other areas of knowledge not covered by the population of this study and validated by student representatives from the business area and by three researchers/teachers of stricto sensu courses in psychology, in order to determine the reliability of the instrument and adjust the description of some statements with the aim of improving the understanding of them. The MCSAB-SS is a numerical scale and uses labels to indicate intensity at the extremities and varies from 0 (never) to 5 (often) points, Finally, Block III focused on characterizing the respondents. The MCSAB-SS is shown in Table 1. 


\section{Table 1}

Meurer and Costa Scale of Academic Behaviors - Stricto Sensu

\begin{tabular}{|c|c|}
\hline ID & Academic citizenship behaviors \\
\hline ACB1 & I use the institution's equipment responsibly. \\
\hline ACB2 & When asked, I review my fellow students' scientific papers and tasks. \\
\hline ACB3 & I collaborate with the formation of study and scientific research discussion groups. \\
\hline ACB4 & I'm strongly dedicated to carrying out the postgraduation activities. \\
\hline ACB5 & $\mathrm{I}$ 'm proactive regarding the postgraduation activities. \\
\hline ACB6 & $\mathrm{I}$ 'm assiduous regarding the postgraduation activities. \\
\hline ACB7 & When asked, I volunteer in postgraduate program activities, even when I don't benefit directly. \\
\hline ACB8 & I take part and aim to get involved in student councils or representations with the collegiate or the teaching institution. \\
\hline ACB9 & I'm punctual, even in activities that aren't carried out in the classroom. \\
\hline ACB10 & I respect the deadlines of the postgraduation activities. \\
\hline ACB11 & During classes and in the study environments, I try to be quiet and only talk at appropriate times. \\
\hline ACB12 & I help fellow students with difficulties understanding the contents of the disciplines. \\
\hline ACB13 & I help fellow students in their scientific research. \\
\hline ACB14 & In the classes and the study environments, I take part in discussions that help in understanding particular scientific subjects. \\
\hline ACB15 & I offer help to fellow students, even when I don't have to. \\
\hline ACB16 & I debate and give constructive criticism to the scientific research of fellow students. \\
\hline ACB17 & I listen to and support my fellow students in their personal problems. \\
\hline ACB18 & I emotionally support and motivate my fellow students at difficult times in the postgraduation. \\
\hline ACB19 & $\begin{array}{l}\text { Even when not asked, I volunteer to share or loan study material used in disciplines or in the elaboration of scientific research to my } \\
\text { fellow students. }\end{array}$ \\
\hline ACB20 & I share academic experiences that may be useful to fellow postgraduate students. \\
\hline ACB21 & I divulge information on courses, contests, events, and other useful information, even with those who aren't in my closest circle. \\
\hline ACB22 & I don't criticize those with different opinions from mine. \\
\hline ACB23 & I try to have empathy and understand the limitations of my fellow students. \\
\hline ACB24 & I avoid interrupting my teachers and fellow students when they're speaking, enabling the reasoning to be concluded. \\
\hline ACB25 & I try to be respectful and polite in my criticisms and opinions. \\
\hline ACB26 & I try to establish friendships and socialize with my fellow postgraduate students outside the university environment. \\
\hline ACB27 & I take part in inclusions and conversations during breaks between the postgraduation activities. \\
\hline ACB28 & I try to include new students and interact with most of the postgraduate students. \\
\hline
\end{tabular}

\section{Counterproductive academic behaviors}

CAB1 I eat food that makes noise or smells in study rooms and research laboratories.

CAB2 I'm disorganized in the university environment I go to for studies.

CAB3 I use the institution's equipment or resources for activities unrelated to postgraduation (e.g. computers to access social networks for amusement).

CAB4 Because I wasn't paying attention, I've already wrongly interpreted e-mails, instructions, regulations, and other information inherent to the postgraduation.

CAB5 I arrive late to the postgraduation classes.

CAB6 I arrive late to postgraduation meetings.

CAB7 I use messaging apps, social networks, and surf the internet for amusement during the postgraduation classes.

CAB8 I barely take part in discussions and activities during the classes.

CAB9 I procrastinate and put off carrying out the postgraduation activities close to deadlines.

CAB10 I invent excuses to justify handing in late or being late in carrying out the postgraduation activities.

CAB11 I read the prior material addressed in class superficially.

CAB12 During the classes, I take part in parallel conversations that are unrelated to the subject being addressed.

CAB13 I take part in parallel conversations in the laboratories or study rooms while other fellow students are studying in the same environment.

CAB14 I make comments during the classes that aren't related with the subject that is being discussed. 
Table 1

Cont.

\section{Counterproductive academic behaviors}

CAB15 I criticize the teachers, employees, or the program as a whole to others.

CAB16 If necessary, I include the name of other people in the authorship of scientific articles, even without them having actively participated in elaborating the research.

CAB17 If necessary, I ask for my name to be included in the authorship of scientific articles, even without having actively participated in elaborating the research.

CAB18 When I fail, I tend to blame my lack of success on teachers or fellow students.

CAB19 I avoid taking part in university activities that go beyond those commonly carried out in the postgraduation (e.g. not helping in CAB19 scientific events, not wanting to be a student representative).

CAB20 I comment to others that the postgraduation is exhausting, but in a way I'm proud of dedicating too much time to the postgraduation activities.

CAB21 I hope fellow students I don't like are unable to achieve scientific publications.

CAB22 I fight, even if quietly, to have more scientific publications than my fellow students.

CAB23 I get annoyed if I perceive I'm being recognized less than my fellow students and fight for the attention of teachers or the orientator.

CAB24 If I get the chance, I'Il hinder a classmate I've had grievances with in the past.

CAB25 When some fellow students fails, I criticize their attitudes to other people.

CAB26 I often raise my tone of voice when confronted in academic discussions carried out in the postgraduation course.

CAB27 I tell inappropriate jokes about my fellow students.

CAB28 I gossip to other people or tell them things I discover in the postgraduation course, even if I'm unsure they're true.

CAB29 I speak ill of fellow students to teachers.

CAB30 I omit information that may give me advantages, even when I know it would be important for other students.

CAB31 I barely interact with students from other research groups or laboratories.

CAB32 I'm individualistic and for that reason I carry out the postgraduation tasks alone.

CAB33 I often monitor my fellow postgraduate students' personal lives.

CAB34 I make negative and pessimistic comments and perceive I end up discouraging the other postgraduate students.

$I D=$ identification

Source: Elaborated by the authors.

The CIPS was subjected to two rounds of pre-tests in order to validate the respondents' understanding of the translation of the research instrument, with some orthographic adjustments being carried out. Given the pretest results, there was the need to exclude four statements (IP1, IP2, IP19, IP20) as they did not present satisfactory factorial indicators, where the Cronbach's alpha found after the exclusions was 0.928 , the same as occurred in the research of French, Ullrich-French, and Follman (2008). In the MCSAB-SS, 28 statements represent ACBs and 34 represent $C A B s$. Due to unsatisfactory factorial indicators, three $\mathrm{ACB}$ statements (ACB1, $\mathrm{ACB} 2$, and $\mathrm{ACB} 21$ ) and nine $\mathrm{CAB}$ statements (CAB4, CAB5, CAB6, CAB8, CAB15, CAB16, CAB17, CAB29, and CAB33) were excluded. The Cronbach's alpha found after the exclusions in the ACB dimension was 0.874 and in the $\mathrm{CAB}$ dimension it was 0.816 .

Regarding the ethical and methodological concerns, the research obtained approval from the research ethics committee of the university with which the researchers are affiliated, recorded in the Brazil Platform (CCAE:
95480818.9.0000.0102). Authorization was obtained via email from Dra. Pauline Rose Clance to use and translate the CIPS, which was done by a sworn translator.

Initially, 2,259 participations in the study were obtained. Of these, nine were students of undergraduate courses, nine were from specialization courses, six from master of business administration (MBA) courses, 10 from professional doctorates, and nine from post-doctorate courses, which were not considered valid for analysis as they did not form part of the investigation's target group. Of the 2,216 responses remaining, 383 were incomplete, which were also excluded from the sample. Finally, 17 participations were discarded as they were not from students affiliated with business area programs. The 1,816 remaining responses were considered valid to be analyzed, representing $80.39 \%$ of the participations collected and $11.37 \%$ of the population of students enrolled in 2018 in academic master's, professional master's, and academic doctorate courses in the business area.

The information on the students' personal characteristics is listed in Table 2. 
Table 2

Profile of the respondents - Personal characteristics

\begin{tabular}{|c|c|c|c|c|c|}
\hline Gender & $\mathbf{n}$ & $\%$ & Age* (years) & $\mathbf{n}$ & $\%$ \\
\hline Female & 930 & 51.21 & Part 1: from 21 to 29 & 567 & 31.22 \\
\hline Male & 852 & 46.92 & Part 2: from 30 to 33 & 377 & 20.76 \\
\hline Agender or non-binary & 12 & 0.66 & Part 3: from 34 to 40 & 448 & 24.67 \\
\hline I prefer not to answer & 22 & 1.21 & Part 4: from 41 to 66 & 424 & 23.35 \\
\hline Region of the teaching institution & $\mathbf{n}$ & $\%$ & Color or ethnicity & $\mathbf{n}$ & $\%$ \\
\hline Central-West & 140 & 7.71 & Yellow & 50 & 2.75 \\
\hline Northeast & 272 & 14.98 & White & 1.280 & 70.48 \\
\hline North & 44 & 2.42 & Indigenous & 4 & 0.22 \\
\hline Southeast & 840 & 46.25 & Brown & 392 & 21.59 \\
\hline South & 520 & 28.64 & Black & 90 & 4.96 \\
\hline
\end{tabular}

* = calculated by quartile.

Source: Elaborated by the authors.

Among the 1,816 students who compose the final research sample, $51.21 \%$ identify with the female gender and are distributed in age groups that form the total interval from 21 to 66 years-old. Most of the students are linked to courses in the Southeast region (46.25\%) and, in relation to color or ethnicity, most of those composing the sample state they are white (70.48\%), followed by brown (21.59\%), black (4.96\%), yellow (2.75\%), and indigenous $(0.22 \%)$. Table 3 presents the sample dispersion by course and area of knowledge investigated.

Table 3

Profile of the respondents - Distribution by course group

\begin{tabular}{|c|c|c|c|c|c|c|c|c|}
\hline Group & Total (n) & $\%$ & $\begin{array}{c}\text { Academic } \\
\text { master's (n) }\end{array}$ & $\%$ & $\begin{array}{c}\text { Academic } \\
\text { doctorate (n) }\end{array}$ & $\%$ & $\begin{array}{l}\text { Professional } \\
\text { master's (n) }\end{array}$ & $\%$ \\
\hline Administration & 1,331 & 73.29 & 396 & 62.86 & 395 & 69.42 & 540 & 87.52 \\
\hline Accounting & 205 & 11.29 & 110 & 17.46 & 65 & 11.42 & 30 & 4.86 \\
\hline Economics & 280 & 15.42 & 124 & 19.68 & 109 & 19.16 & 47 & 7.62 \\
\hline Total & 1,816 & 100.00 & 630 & 100.00 & 569 & 100.00 & 617 & 100.00 \\
\hline
\end{tabular}

Source: Elaborated by the authors.

There is a greater concentration of students in administration courses (73.29\%), followed by economics (15.42\%) and accounting (11.29\%). With relation to the data analysis, these were extracted from the SurveyMonkey ${ }^{\circledR}$ online platform and organized in the Microsoft Office Excel ${ }^{\circledR}$ software. Next, the analyses were carried out using the following statistical techniques: (i) descriptive statistics; (ii) exploratory factor analysis; and (iii) the Spearman's correlation.

Exploratory factor analysis was used with the aim of identifying the dimensions of the constructs and, when necessary, reducing the dimensions of the data based on the creation of factors (Fávero \& Belfiore, 2017). Due to the non-normality of the data verified by the KolmogorovSmirnov test, by the histogram analysis, and by the normal Q-Q plot, in this study the non-parametric Spearman's correlation technique is used to verify $\mathrm{TH}_{1}$ and $\mathrm{TH}_{2}$, which varies from -1 to 1 , to indicate the association between two variables when the parametric test assumptions are not fulfilled (Field, 2009). The Spearman's correlation was chosen given that the study summarily addresses subjective variables, this technique having been used in the analyses of Grubb Iii and McDowell (2012), Vergauwe et al. (2015), and Neureiter and Traut-Mattausch (2016).

\section{RESULTS}

The criteria used in the exploratory factor analysis are preference commonalities above 0.50 , where commonalities above 0.30 may be acceptable for samples with more than 500 observations (Field, 2009). Another 
criterion adopted in the formation of the factors consists of factor loadings above 0.40 (Hair, Black, Babin, Anderson, \& Tatham, 2009), where the variables that do not reach that level of contribution are eliminated. Hair et al. (2009) also recommend making efforts so that each factor has at least five variables, where a minimum of three per factor is accepted (Diamantopoulos \& Siguaw, 2000). With relation to the quality of the global fit of the factors, the following were prioritized: a Kaiser-Meyer-
Olkin (KMO) index above 0.70 (Fávero \& Belfiore, 2017), a Bartlett's sphericity test with a significance level below 0.050 ( $\mathrm{p}$-value $<0.050$ ), a measure of sampling adequacy (MSA) close to or above 0.70 (Hair et al., 2009), and an explained variance in the factor retention of at least 50\% (Marôco, 2007). After carrying out analysis rounds and fulfilling the factor indicator criteria, the factors and grouped statements were identified, as presented in Table 4.

\section{Table 4}

Formation of the construct dimensions

\begin{tabular}{|c|c|}
\hline Impostor phenomenon & Statements \\
\hline $\begin{array}{l}\text { Factor } 1 \text { - Falseness and Underestimation (IP1): feelings of farce and doubts about their abilities to } \\
\text { achieve success. }\end{array}$ & $\begin{array}{l}\text { F14, F13, F15, F18, F6, F17, F4, } \\
\text { F7, F12, F16, F8, F10, F3 }\end{array}$ \\
\hline $\begin{array}{l}\text { Factor } 2 \text { - Luck or Chance (IP2): attributions of success to random situations, related to fate or } \\
\text { coincidences. }\end{array}$ & F11, F9, F5 \\
\hline Academic citizenship behavior & Statements \\
\hline $\begin{array}{l}\text { Factor } 1 \text { - Academic Cooperation (CI1): behaviors of helping fellow students in developing scientific } \\
\text { research or in understanding subjects addressed during the disciplines. }\end{array}$ & $\begin{array}{l}\text { ACB12, ACB13, ACB16, ACB14, } \\
\text { ACB15 }\end{array}$ \\
\hline $\begin{array}{l}\text { Factor } 2 \text { - Academic Engagement }(\mathrm{Cl} 2) \text { : aspects of proactivity and volunteering during the postgraduation } \\
\text { involving dedication and academic collaboration. }\end{array}$ & ACB7, ACB3, ACB5, ACB8, ACB4 \\
\hline $\begin{array}{l}\text { Factor } 3 \text { - Interpersonal Support }(\mathrm{Cl} 3) \text { : supporting fellow students with personal problems or helping in } \\
\text { broader situations than those specifically related to scientific research or to the content addressed in the } \\
\text { disciplines. }\end{array}$ & ACB17, ACB18, ACB19, ACB20 \\
\hline $\begin{array}{l}\text { Factor } 4 \text { - Academic Commitment }(\mathrm{Cl} 4) \text { : the student's commitment to the obligations of the stricto sensu } \\
\text { course, such as punctuality, meeting deadlines, and attendance. }\end{array}$ & ACB10, ACB9, ACB6 \\
\hline $\begin{array}{l}\text { Factor } 5 \text { - Academic Empathy }(\mathrm{Cl} 5) \text { : elements related to respect and healthy coexistence with fellow } \\
\text { students, marked by attitudes of avoiding interrupting those speaking, being quiet in study environments, } \\
\text { and being respectful and polite with others. }\end{array}$ & ACB25, ACB24, ACB23, ACB11 \\
\hline $\begin{array}{l}\text { Factor } 6 \text { - Academic Integration (Cl6): aspects of interpersonal interaction with fellow postgraduate } \\
\text { students. }\end{array}$ & ACB27, АCB26, АCB28 \\
\hline Counterproductive academic behavior & Statements \\
\hline $\begin{array}{l}\text { Factor } 1 \text { - Academic Disrespect (CO1): disrespectful attitudes, such as raising their tone of voice, speaking } \\
\text { ill of fellow students, and blaming their faults on others. }\end{array}$ & $\begin{array}{l}\text { CAB26, CAB27, CAB28, CAB25, } \\
\text { CAB34, CAB18 }\end{array}$ \\
\hline Factor 2 - Academic Competitiveness (CO2): fighting for academic recognition, attention, and prestige. & $\begin{array}{l}\text { CAB22, CAB23, CAB21, CAB30, } \\
\text { CAB24 }\end{array}$ \\
\hline $\begin{array}{l}\text { Factor } 3 \text { - Academic Disengagement (CO3): disinterest and distraction during the activities carried out in } \\
\text { the stricto sensu course. }\end{array}$ & CAB12, CAB13, CAB14, CAB7 \\
\hline $\begin{array}{l}\text { Factor } 4 \text { - Academic Procrastination (CO4): postponement attitudes when carrying out academic } \\
\text { activities, which can sometimes mean carrying them out superficially. }\end{array}$ & CAB9, CAB10, CAB11 \\
\hline $\begin{array}{l}\text { Factor } 5 \text { - Academic Isolation (CO5): academic individualism, which implies carrying out tasks on their } \\
\text { own and even workaholic practices. }\end{array}$ & CAB31, CAB19, CAB32, САВ20 \\
\hline $\begin{array}{l}\text { Factor } 6 \text { - Academic Indifference (CO6): attitudes that interfere in the collective coexistence due to the } \\
\text { individual being indifferent to the attitudes of their behavior in the eyes of others. }\end{array}$ & $\mathrm{CAB} 1, \mathrm{CAB} 2, \mathrm{CAB} 3$ \\
\hline
\end{tabular}

Source: Elaborated by the authors.

After identifying the two dimensions of the IP and the six dimensions of $\mathrm{ACB}$ and $\mathrm{CAB}$, in order to achieve the research objective, $\mathrm{TH}_{1}$ and $\mathrm{TH}_{2}$ were operationalized based on the Spearman's correlation test. The results are shown in Table 5. 
Table 5

Analysis of the relationship between the impostor phenomenon and academic behavior

\begin{tabular}{|c|c|c|c|c|c|c|c|c|c|c|c|c|c|c|}
\hline & IP1 & IP2 & CI1 & $\mathrm{Cl} 2$ & $\mathrm{Cl} 3$ & $\mathrm{Cl} 4$ & $\mathrm{Cl} 5$ & $\mathrm{Cl} 6$ & $\mathrm{CO} 1$ & $\mathrm{CO} 2$ & $\mathrm{CO} 3$ & $\mathrm{CO} 4$ & $\mathrm{CO} 5$ & $\mathrm{CO6}$ \\
\hline IP1 & 1 & & & & & & & & & & & & & \\
\hline IP2 & $-0.078^{* *}$ & 1 & & & & & & & & & & & & \\
\hline $\mathrm{Cl} 1$ & $-0.056^{*}$ & -0.007 & 1 & & & & & & & & & & & \\
\hline $\mathrm{Cl} 2$ & $-0.086^{* *}$ & $-0.062^{* *}$ & 0.030 & 1 & & & & & & & & & & \\
\hline $\mathrm{Cl} 3$ & $0.175^{* *}$ & $-0.073 * *$ & 0.019 & 0.010 & 1 & & & & & & & & & \\
\hline $\mathrm{Cl} 4$ & $-0.109^{* *}$ & $-0.152^{* *}$ & 0.016 & -0.009 & 0.007 & 1 & & & & & & & & \\
\hline $\mathrm{Cl} 5$ & -0.028 & $-0.083^{* *}$ & 0.022 & 0.009 & 0.027 & 0.008 & 1 & & & & & & & \\
\hline $\mathrm{Cl} 6$ & $-0.055^{*}$ & -0.018 & 0.010 & 0.005 & 0.013 & 0.012 & 0.014 & 1 & & & & & & \\
\hline $\mathrm{CO} 1$ & $0.080^{* *}$ & $0.114^{* *}$ & -0.025 & 0.005 & -0.038 & $-0.062^{* *}$ & $-0.257^{* *}$ & -0.029 & 1 & & & & & \\
\hline $\mathrm{CO} 2$ & $0.136^{* *}$ & 0.009 & $0.061^{* *}$ & $0.184^{* *}$ & -0.027 & $0.065^{* *}$ & $-0.066^{* *}$ & -0.029 & $-0.158^{* *}$ & 1 & & & & \\
\hline $\mathrm{CO} 3$ & $0.090^{* *}$ & 0.039 & $-0.120^{* *}$ & 0.002 & $0.119 * *$ & $-0.076^{* *}$ & $-0.298^{* *}$ & $0.207^{* *}$ & $-0.075^{* *}$ & 0.016 & 1 & & & \\
\hline $\mathrm{CO} 4$ & $0.185^{* *}$ & $0.205^{* *}$ & $-0.113^{* *}$ & $-0.248^{* *}$ & -0.025 & $-0.478^{* *}$ & -0.029 & -0.035 & -0.036 & $-0.055^{*}$ & 0.037 & 1 & & \\
\hline $\mathrm{CO} 5$ & $0.152 * *$ & 0.022 & $-0.207^{* *}$ & $-0.339 * *$ & $-0.112^{* *}$ & $0.087^{* *}$ & 0.006 & $0.326^{* *}$ & -0.003 & -0.020 & 0.025 & 0.005 & 1 & \\
\hline $\mathrm{CO} 6$ & 0.044 & $0.109 * *$ & -0.026 & -0.011 & $0.079^{* *}$ & $-0.085^{* *}$ & $-0.110^{* *}$ & 0.016 & $-0.110^{* *}$ & $-0.090 * *$ & -0.010 & -0.040 & -0.020 & 1 \\
\hline
\end{tabular}

$\mathrm{Cl} 1$ = Academic Cooperation; $\mathrm{Cl} 2=$ Academic Engagement; $\mathrm{Cl} 3=$ Interpersonal Support; $\mathrm{Cl} 4=$ Academic Commitment; $\mathrm{Cl} 5=$ Academic Empathy; Cl6 = Academic Integration; CO1 = Academic Disrespect; $\mathrm{CO} 2$ = Academic Competence; CO3 = Academic Disengagement; CO4 = Academic Procrastination; CO5 = Academic Isolation; CO6 = Academic Indifference; IP1 = Falseness and Underestimation; IP2 = Luck and Chance.

** $=p<0.01 ;{ }^{*}=p<0.05$.

Source: Elaborated by the authors.

The Spearman's correlation indicated significant associations between the dimensions of the IP and those of citizenship behavior and counterproductive behavior. With relation to $\mathrm{ACB}$, the correlations indicate a negative association between the IP in the Falseness and Underestimation dimension $(\mathrm{r}=-0.056 ; \mathrm{p}<0.05)$ and Academic Cooperation behaviors. Thus, students with higher levels of feelings of falseness and underestimation of their abilities tend to cooperate less with fellow students in developing scientific research, in understanding contents addressed in the disciplines, and in offering help, even when not asked. In the Luck and Chance dimension, no significant correlation was identified.

With relation to Academic Engagement, a negative relationship with feelings of Falseness and Underestimation $(\mathrm{r}=-0.086 ; \mathrm{p}<0.01)$ and Luck and Chance $(\mathrm{r}=-0.062$; $\mathrm{p}<0.01)$ is noted. Within this context, the behaviors of students who underestimate their abilities and/or believe that their success derives from random facts are negatively associated with attitudes that involve participation in university events and student councils, proactivity, and high dedication to postgraduation activities.

For Interpersonal Support, opposing relationships are noted, in which there is a positive association with feelings of Falseness and Underestimation $(r=0.175 ; p<0.01)$ and a negative relationship in the Luck or Chance dimension $(\mathrm{r}=-0.073 ; \mathrm{p}<0.01)$. So, the behaviors of postgraduate students who underestimate their competences tend to be positively associated with attitudes of supporting fellow students with personal problems and sharing university experiences and materials to be used in the postgraduation activities. In contrast, students with higher levels of attributing their success to luck or chance have a negative association with such behaviors.

With relation to Academic Commitment, negative associations were identified both for the Falseness and Underestimation dimension $(\mathrm{r}=-0.109 ; \mathrm{p}<0.01)$ and for Luck and Chance $(r=-0.152 ; \mathrm{p}<0.01)$. In this sense, more intense levels of both dimensions of the IP are negatively associated with deadlines, punctuality, and attendance in the postgraduation activities.

Concerning Academic Empathy, no significant correlation was identified for feelings of Falseness and Underestimation ( $r=-0.028 ; p>0.05)$ and, in contrast, there was a negative and significant correlation for Luck or Chance $(\mathrm{r}=-0.083 ; \mathrm{p}<0.01)$. Based on the results, it is observed that postgraduate students who attribute their success to luck or chance present lower levels of academic empathy, embodied in respect for fellow students and teachers, as well as in speaking and expressing thoughts respectfully.

For the sixth dimension of ACB, Academic Integration, there was a significant correlation only for the Falseness and Underestimation dimension $(\mathrm{r}=-0.055 ; \mathrm{p}<0.05)$. Within this context, the behavior of students with more intense levels of feelings of falseness and underestimation tends to be less frequently associated with integrating with fellow postgraduate students and with getting involved with students joining the postgraduation course. 
Based on the results analyzed, $\mathrm{TH}_{1}$ - the IP is negatively related with the ACB of stricto sensu students in the business area - cannot be totally accepted, as there was a positive and significant correlation between Interpersonal Support and feelings of Falseness and Underestimation $(\mathrm{r}=$ $0.175 ; \mathrm{p}<0.05)$. However, the other significant correlations were aligned to the assumption of $\mathrm{TH}_{1}$, indicating that higher levels of the IP are negatively associated with ACBs.

These results are in line with those found by Grubb Iii and McDowell (2012), Vergauwe et al. (2015), Arkan (2016), and Neureiter and Traut-Mattausch (2016), in which people with higher levels of the IP tend to dedicate less time to activities or attitudes that transcend the formal academic role, given that the time employed in such actions could hinder the performance achieved in formal obligations and expose these individuals to the judgement of others.

Regarding $\mathrm{CAB}$, the correlations indicated a positive relationship with the IP. For attitudes of Academic Disrespect, there are significant correlations both for feelings of Falseness and Underestimation $(r=0.080$; $\mathrm{p}<0.01)$ and for Luck and Chance $(\mathrm{r}=0.114 ; \mathrm{p}<0.01)$. Therefore, the behaviors of students with higher levels of the IP are more intensely associated with joking inappropriately with fellow students, raising their tone of voice in academic discussions, spreading rumors occurring in the postgraduation course without knowing if they are true, criticizing fellow students' flaws to others, being pessimistic, and, if they fail, blaming others.

In the Academic Competitiveness dimension, there was a significant correlation only with feelings of Falseness and Underestimation $(\mathrm{r}=0.136 ; \mathrm{p}<0.01)$. Thus, the behaviors of students who underestimate their competences are positively associated with fighting for scientific publications, they seek to be more recognized than fellow students, they hope fellow students they do not like are unable to achieve publications, and they may omit information and hamper those they have had grievances with in the past.

For Academic Disengagement, a significant correlation was identified in the Falseness and Underestimation dimension $(r=0.090 ; p<0.01)$. Attitudes of academic disengagement are embodied in participating in parallel conversations in classes, laboratories, and study rooms, as well as commenting on subjects that are not being discussed and surfing the internet during class for amusement. Thus, the behaviors of students with more intense feelings of falseness and underestimation of their abilities tend to be associated with these attitudes of academic disengagement.
Concerning Academic Procrastination, a positive and significant association is noted with the Falseness and Underestimation $(\mathrm{r}=0.185 ; \mathrm{p}<0.01)$ and Luck or Chance $(r=0.205 ; p<0.01)$ dimensions of the IP. The behaviors of postgraduate students with higher levels of impostorism tend to be positively associated with procrastination, which is embodied in carrying out postgraduation activities close to deadlines, inventing excuses to justify delays in carrying out stricto sensu activities, and doing the reading suggested during the classes superficially. This finding is in line with the one presented by Chassangre and Callahan (2017), where people with more intense levels of the IP tend to postpone carrying out tasks with the aim of protecting their self-esteem when presented with the possibility of failure.

With relation to Academic Isolation, significant differences were perceived for the Falseness and Underestimation dimension $(\mathrm{r}=0.152 ; \mathrm{p}<0.01)$. Higher levels of the IP are positively linked to little interaction with fellow students in laboratories or research groups, avoiding taking part in activities that go beyond those commonly carried out in the postgraduation course, being more individualistic and carrying out tasks alone, as well as being proud and commenting that the postgraduation course is more exhausting. Regarding the latter behavior, this is in line with the workaholic attitudes that characterize impostors, as mentioned by Chassangre and Callahan (2017).

Finally, Academic Indifference was significantly associated with the Luck or Chance dimension $(r=0.109$; $\mathrm{p}<0.01)$. With this, postgraduate students who relate achieving success to luck or chance tend to more often present behaviors inherent to consuming food in the research laboratories, disorganization in the university environment, and using the institution's equipment for activitites unrelated with postgraduation.

Thus, $\mathrm{TH}_{2}$ - the IP is positively related with the $\mathrm{CAB}$ of stricto sensu students in the business area - can be totally accepted, given that all the significant correlations between the IP dimensions and counterproductive behaviors were positive. The findings are aligned with those presented by Arkan (2016), where the IP is positively associated with counterproductive behaviors displayed in the university environment.

Based on the results obtained in the analysis of $\mathrm{TH}_{1}$ and $\mathrm{TH}_{2}$, the research objective, which concerns the relationship between the IP and the academic behavior of stricto sensu postgraduate students in business area courses, can be answered as follows: higher levels of the IP are generally negatively associated with ACBs, with 
the exception of Interpersonal Support, which for the Falseness and Underestimation dimension is positively correlated. For the CABs, all the correlations were negative, enabling the full acceptance of the theoretical hypothesis. The evidence indicates that not all the IP dimensions are significantly associated with academic behaviors, where the strongest associations are noted for CABs such as Academic Procrastination and Academic Isolation. For the ACBs, there was a positive association for Interpersonal Support and a more intense negative correlation for Academic Commitment. Table 6 presents a summary of $\mathrm{TH}_{1}$ and $\mathrm{TH}_{2}$.

Table 6

Summary of theoretical hypotheses (TH) 1 and 2

\begin{tabular}{lll}
\hline Hypothesis & Description & Results \\
\hline $\mathrm{TH}_{1}$ & $\begin{array}{l}\text { The impostor phenomenon is negatively related with the academic citizenship behavior of } \\
\text { stricto sensu students in the business area. }\end{array}$ & $\begin{array}{l}\text { Partially accepted (opposite result } \\
\text { for Interpersonal Support) }\end{array}$ \\
\hline $\mathrm{TH}_{2}$ & $\begin{array}{l}\text { The impostor phenomenon is positively related with the counterproductive academic } \\
\text { behavior of stricto sensu students in the business area. }\end{array}$ & Totally accepted \\
\hline
\end{tabular}

Source: Elaborated by the authors.

The findings are shown to be aligned with the behavioral characteristics of the IP, in terms of procrastination, social isolation, and individualism (Chassangre \& Callahan, 2017). In addition, Cummings et al. (2017) mentions that people with low emotional stability and high levels of anxiety, traits of impostors, present more intense counterproductive behaviors, which supports the findings of this study.

\section{CONCLUSION}

This study analyzed the relationship between the IP and the academic behavior of stricto sensu postgraduate students of business area courses. The associations pointed to the existence of a positive and significant relationship between the dimensions of the IP and some dimensions of $\mathrm{CAB}$, enabling the acceptance of the proposed theoretical hypothesis. In contrast, most of the significant correlations between the ACBs and the dimensions of the IP were negative, with the exception of Interpersonal Support, and thus there was partial acceptance of the hypothesis proposed for this relationship.

In the academic field, this study uses the MCSAB-SS research instrument, which is able to measure citizenship and counterproductive academic behaviors displayed in Brazilian postgraduation courses, enabling the development of new investigations into the topic. It was discovered that the discretionary behaviors displayed in stricto sensu permeate various aspects of the academic context, whether they are citizenship or counterproductive.

The results negatively associated the IP with ACBs and positively associated it with CABs. Postgraduate students with the IP may not be adequately engaging in the activities that permeate stricto sensu, damaging the climate and culture of cooperation needed to carry out the academic activities. With this, the results obtained by postgraduation programs, such as scientific publications and extension projects, may be hindered by the disengaged behaviors of these students.

From the student perspective, the performance and knowledge of these students may be being hampered by behaviors that are not ideal, such as procrastination, workaholicism, and individualism, among other negative attitudes. Such attitudes may be prejudicial to professional development, given that commitment to the stricto sensu tasks and relationship networks are essential for the development of various academic activities, such as research, leadership roles, and teaching.

Also related to students' attitudes, in social terms, preparing them to be good professionals means incentivizing them to display citizenship behaviors. In this sense, maximizing such attitudes in postgraduate students may collaborate in training individuals who are able to meet the social demands in the environment in which they will carry out their professional activities. By the end of the course, stricto sensu postgraduates are expected to have developed abilities for analyzing and solving complex problems, managing projects, displaying critical thinking, as well as leadership and time management skills (Andrade, 2018), which are abilities that may be affected both by counterproductive attitudes, such as disengagement, and by characteristics of the IP, such as procrastination (Chassangre \& Callahan, 2017). 
In interventionist terms, the literature presents some actions that could collaborate in minimizing impostor feelings. The formation of conversation groups among students is suggested in order to promote the sharing of personal experiences and overcome situations that can cause doubts in relation to their competences (Thompson, Davis, \& Davidson, 1998). With this, the IP, as well as its impacts, can be minimized not only for the individual, but also in the organizational environment.

It is recommended that the actions for improvement focus on group activities and academic engagement, with the aim of incentivizing cultural involvement, given that the behavior of impostors is normally geared toward being "off the radar" (Grubb Iii \& McDowell, 2012), that is, toward attitudes and behaviors that mean they go unnoticed by fellow students and teachers. This is one of the reasons for the positive correlation between the dimensions of the IP and the counterproductive behaviors of Academic Isolation and Academic Indifference.

Within this context, strengthening the display and beliefs of citizenship and counterproductive behaviors and exposing their influence on the effectiveness of stricto sensu courses could help in promoting student engagement actions. Reinforcing the importance of taking part in student representations, promoting student rotation in extension projects, and incentivizing the formation of study groups and team activities are actions that could be carried out by teachers and the coordination with the aim of fostering citizenship behaviors.

Finally, the proposal of a research instrument and addressing a field that has barely been explored, such as stricto sensu postgraduation, while providing pioneering contributions, also limit comparisons with previous studies. The strictly quantitative approach is one limitation of the research and is an aspect that could be combatted with qualitative approaches in order to complement the evidence. It is suggested that the MCSAB-SS be applied among students of courses in other areas of knowledge with the aim of verifying and comparing the results obtained. Moreover, few studies are noted that address the IP within the Brazilian context and in stricto sensu, as well as its relationship with academic behaviors, thus making more comprehensive discussions on the topic based on previous studies impossible.

\section{REFERENCES}

Allison, B. J., Voss, R. S., \& Dryer, S. (2001). Student classroom and career success: The role of organizational citizenship behavior. Journal of Education for Business, 76(5), 282-288. https://doi.org/10.1080/08832320109599650

Andrade, R. de O. (2018). À procura da versatilidade. Retrieved from http://revistapesquisa.fapesp.br/wp-content/ uploads/2018/02/094-097_carreiras_264.pdf

Arkan, Ö. (2016). Determinants of organizational citizenship and counterproductive work behavior: The role of personality, job characteristics, job satisfaction and organizational commitment dilemma (Tese de Doutorado). Middle East Technical University, Ancara. Retrieved from http://etd.lib.metu.edu.tr/ upload/12620109/index.pdf

Barnard, C. (1938). The functions of the executive. Cambridge, MA: Harvard University.

Chassangre, K. (2014). Le phénomène de l'imposteur, la peur qui mine la réussite. Journal de Therapie Comportementale et Cognitive, 24(1), 32-38.

Chassangre, K., \& Callahan, S. (2017). J’ai réussi, j’ai de la chance je serai démasqué: Revue de littérature du syndrome de l'imposteur. Pratiques Psychologiques, 23(2), 97-110.

Clance, P. R. (1985). The impostor phenomenon: Overcoming the fear that haunts your success. Atlanta, GA: Peachtree.

Clance, P. R., \& Imes, S. A. (1978). The imposter phenomenon in high achieving women: Dynamics and therapeutic intervention. Psychotherapy: Theory, Research \& Practice, 15(3), 241-247. https://doi.org/10.1037/h0086006
Clance, P. R., \& O'Toole, M. A. (1987). The imposter phenomenon. Women \& Therapy, 6(3), 51-64. https://doi. org/10.1300/J015V06N03_05

Cokley, K., Awad, G., Smith, L., Jackson, S., Awosogba, O., Hurst, A., ... Roberts, D. (2015). The roles of gender stigma consciousness, impostor phenomenon and academic selfconcept in the academic outcomes of women and men. Sex Roles, 73(9-10), 414-426.

Cowman, S. E., \& Ferrari, J. R. (2002). "Am I for real?" Predicting impostor tendencies from self-handicapping and affective components. Social Behavior and Personality: An International Journal, 30(2), 119-125. https://doi.org/10.2224/ sbp.2002.30.2.119

Credé, M., \& Niehorster, S. (2009). Individual difference influences on self-focused and other-focused counterproductive student behaviors. Personality and Individual Differences, 47(7), 769-776. https://doi. org/10.1016/j.paid.2009.06.018

Cummings, D. J., Poropat, A. E., Loxton, N. J., \& Sheeran, N. (2017). Development and initial validation of a multidimensional student performance scale. Learning and Individual Differences, 59(March), 22-33. https://doi. org/10.1016/j.lindif.2017.08.008

Dalal, R. S. (2005). A meta-analysis of the relationship between organizational citizenship behavior and counterproductive work behavior. Journal of Applied Psychology, 90(6), 12411255. https://doi.org/10.1037/0021-9010.90.6.1241 
Diamantopoulos, A., \& Siguaw, J. A. (2000). Introducing lisrel. London: Sage.

Dudău, D. P. (2014). The relation between perfectionism and impostor phenomenon. Procedia - Social and Behavioral Sciences, 127(1), 129-133.

Elsharnouby, T. H. (2015). Student co-creation behavior in higher education: The role of satisfaction with the university experience. Journal of Marketing for Higher Education, 25(2), 238-262. https://doi.org/10.1080/08841241.2015.1059919

Fávero, L. P., \& Belfiore, P. (2017). Manual de análise de dadosEstatística e modelagem multivariada com Excel', SPSS $S^{\circ}$ Stata. Rio de Janeiro, RJ: Elsevier.

Ferrari, J. R. (2005). Impostor tendencies and academic dishonesty: Do They cheat their way success? Social Behavior and Personality: An International Journal, 33(1), 11-18.

Field, A. (2009). Descobrindo a Estatística usando o SPSS (2a. ed.). Porto Alegre, RS: Artmed.

Freire, C. (2014). Academic misconduct among Portuguese economics and business undergraduate students - A comparative analysis with other major students. Journal of Academic Ethics, 12(1), 43-63. https://doi.org/10.1007/s10805013-9199-2

French, B. F., Ullrich-French, S. C., \& Follman, D. (2008). The psychometric properties of the Clance Impostor Scale. Personality and Individual Differences, 44(5), 1270-1278.

Gore, J. S., Davis, T., Spaeth, G., Bauer, A., Loveland, J. M., \& Palmer, J. K. (2014). Subjective well-being predictors of academic citizenship behavior. Psychological Studies, 59(September), 299-308. https://doi.org/10.1007/s12646-0140235-0

Grubb Iii, W. L., \& McDowell, W. C. (2012). The imposter phenomenon's impact on citizenship behavior and employee commitment: Flying under the radar. Journal of Business Issues, 1(1), 1-10.

Hair, J. F., Jr., Black, W. C., Babin, B. J., Anderson, R. E., \& Tatham, R. L. (2009). Análise multivariada de dados. Porto Alegre, RS: Bookman.

Harvey, J. C. (1982). The impostor phenomenon and achievement: A failure to internalize success. Dissertation Abstracts International, 42(12-B, Pt 1), 4969-4970.

Imes, S. (1980). The impostor phenomenon as a function of attribution patterns and internalized femininity/masculinity in high achieving women and men. Dissertation Abstracts International, 40(12-B, Pt 1), 5868-5869.

Islam, S., Permzadian, V., Choudhury, R. J., Johnston, M., \& Anderson, M. (2018). Proactive personality and the expanded criterion domain of performance: Predicting academic citizenship and counterproductive behaviors. Learning and Individual Differences, 65(May), 41-49. https://doi. org/10.1016/j.lindif.2018.05.016

Katz, D. (1964). Motivational basis of organizational behavior. Behavioral Science, 9(1), 131-146.

Katz, D., \& Kahn, R. L. (1966). The social psychology of organizations. New York, NY: Wiley.

Kets de Vries, M. F. R. (1989). The impostor syndrome: A disquieting phenomenon in organizational life. New York, NY: Insead.
Khalid, S. A., Jusoff, K., Othman, M., Ismail, M., \& Rahman, N. A. (2010). Organizational citizenship behavior as a predictor of student academic achievement. International Journal of Economics and Finance, 2(1), 65-71.

Khaola, P. P. (2014). The relationships among students' organisational citizenship behaviour and academic performance. Africa Education Review, 11(2), 119-132.

Langford, J., \& Clance, P. R. (1993). The impostor phenomenon: Recent research findings regarding dynamics, personality and family patterns and their implications for treatment. Psychotherapy, 30(3), 495-501. https://doi.org/10.1037/00333204.30.3.495

Levecque, K., Anseel, F., De Beuckelaer, A., Van der Heyden, J., \& Gisle, L. (2017). Work organization and mental health problems in PhD students. Research Policy, 46(4), 868-879. https://doi.org/10.1016/j.respol.2017.02.008

Li, S., Hughes, J. L., \& Thu, S. M. (2014). The links between parenting styles and imposter phenomenon. PSI CHI Journal of Psychological Research, 19(2), 50-57.

Marôco, J. (2007). Análise estatística com utilização do SPSS. Lisboa: Edições Sílabo.

Matos, P. A. V. C. de. (2014). Síndrome do impostor e auto-eficácia de minorias sociais: alunos de contabilidade e administração (Master's Dissertation). Universidade de São Paulo, São Paulo.

McCabe, D. L., Butterfield, K. D., \& Treviño, L. K. (2006). Academic dishonesty in graduate business programs: Prevalence, causes, and proposed action. Academy of Management Learning and Education, 5(3), 294-305. https:// doi.org/10.5465/AMLE.2006.22697018

Meriac, J. P. (2012). Work ethic and academic performance: Predicting citizenship and counterproductive behavior. Learning and Individual Differences, 22(4), 549-553.

Meurer, A. M. (2019). Eis o melhor e o pior de mim : fenômeno impostor e comportamento acadêmico na pós-graduação stricto sensu da área de negócios (Master's Dissertation). Universidade Federal do Paraná, Curitiba.

Neureiter, M., \& Traut-Mattausch, E. (2016). Inspecting the dangers of feeling like a fake: An empirical investigation of the impostor phenomenon in the world of work. Frontiers in Psychology, 7, 1445.

Organ, D. W. (1988). Organizational citizenship behavior: The good soldier syndrome. Lexington, MA: Lexington Books/D. C. Heath and Com.

Organ, D. W., \& Ryan, K. (1995). A meta-analytic review of attitudinal and dispositional predictors of organiational citizenship behavior. Personnel Psychology, 48(4), 775-802.

Parkman, A. (2016). The imposter phenomenon in higher education: Incidence and impact. Journal of Higher Education Theory and Practice, 16(1), 51-61.

Rose, K. (2012). Organizational citizenship behaviors in higher education: Examining the relationships between behaviors and performance outcomes for individuals and institutions. Retrieved from https://pdfs.semanticscholar. org/25ca/9a5209670a0e7ddd090b72a9a491d646159f. pdf?_ga=2.59439145.521909526.15730645641907922079.1568750401 
Sackett, P. R., Berry, C. M., Wiemann, S. A., \& Laczo, R. M. (2006). Citizenship and counterproductive behavior: Clarifying relations between the two domains. Human Performance, 19(4), 441-464. https://doi.org/10.1207/ s15327043hup1904_7

Schmitt, N., Oswald, F. L., Friede, A., Imus, A., \& Merritt, S. (2008). Perceived fit with an academic environment: Attitudinal and behavioral outcomes. Journal of Vocational Behavior, 72(3), 317-335. https://doi.org/10.1016/j. jvb.2007.10.007

Sonnak, C., \& Towell, T. (2001). The impostor phenomenon in British university students: Relationships between self-esteem, mental health, parental rearing style and socioeconomic status. Personality and Individual Differences, 31(6), 863-874.

Spector, P. E., \& Fox, S. (2002). An emotion-centered model of voluntary work behavior. Human Resource Management Review, 12(2), 269-292.

Taylor, A. (2009). The impostor phenomenon: A look at the outside, the inside, and the other side through scholarly personal narrative. Retrieved from https://mountainscholar.org/ handle/10217/34985

Thompson, T., Davis, H., \& Davidson, J. (1998). Attributional and affective responses of impostors to academic success and failure outcomes. Personality and Individual Differences, 25(2), 381-396. https://doi.org/10.1016/S0191-8869(98)00065-8
Thompson, T., Foreman, P., \& Martin, F. (2000). Impostor fears and perfectionistic concern over mistakes. Personality and Individual Differences, 29(4), 629-647.

University or Waterloo. (2016). Impostor phenomenon and graduate students. Retrieved from https://uwaterloo.ca/ centre-for-teaching-excellence/teaching-resources/teachingtips/planning-courses/tips-teaching-assistants/impostorphenomenon-and

Vergauwe, J., Wille, B., Feys, M., De Fruyt, F., \& Anseel, F. (2015). Fear of being exposed: The trait-relatedness of the impostor phenomenon and its relevance in the work context. Journal of Business and Psychology, 30(3), 565-581.

Whelpley, C. E., \& McDaniel, M. A. (2016). Self-esteem and counterproductive work behaviors: A systematic review. Journal of Managerial Psychology, 31(4), 850-863.

Williams, L. J., \& Anderson, S. E. (1991). Job Satisfaction and organizational commitment as predictors of organizational citizenship and in-role behaviors. Journal of Management, 17(3), 601-617. https://doi. org/10.1177/014920639101700305

Zettler, I. (2011). Self-control and academic performance: Two field studies on university citizenship behavior and counterproductive academic behavior. Learning and Individual Differences, 21(1), 119-123. https://doi. org/10.1016/j.lindif.2010.11.002 